\title{
HÁBITO DE CRESCIMENTO DE COLLETOTRICHUM GOSSYPII E C. GOSSYPII VAR. CEPHALOSPORIOIDES EM SEMENTES DE ALGODOEIRO $\left({ }^{1}\right)$
}

\author{
MARIA APARECIDA DE SOUZA TANAKA $\left({ }^{2,5}\right)$, \\ JOSÉ OTAVIO MACHADO MENTEN $\left({ }^{3,5}\right)$ e JOSÉ DA CRUZ MACHADO $\left({ }^{4,5}\right)$
}

\begin{abstract}
RESUMO
Observaçōes sobre o hábito de crescimento de Colletotrichum gossypii e $C$. gossypii var. cephalosporioides em sementes de algodoeiro, inoculadas artificialmente e incubadas a $20-22^{\circ} \mathrm{C}$ durante cinco a sete dias, evidenciaram as seguintes características: (a) em raízes: acérvulos isolados ou em grupos, massa conidial cor branco-suja, alaranjada ou salmão (mais freqüente), setas marrom-escuras, muitas vezes encobertas pela matriz gelatinosa; conídios produzidos também no micélio aéreo ou nas extremidades das setas, onde ficam aderidos, formando pequenos aglomerados; (b) na superfície das sementes: conídios produzidos nos ápices de setas que emergem diretamente do tegumento, ficando aderidos uns aos outros, formando cachos, semelhantes a cadeias, que são vistos brilhantes sob a luz, em estereomicroscópio. As setas férteis são formadas também no micélio aéreo que recobre as sementes, geralmente após cinco dias de incubação. Os acérvulos com massa conidial raramente são visíveis, exceto em sementes danificadas ou mortas. Como característica de $C$. gossypii, observou-se que as sementes exibem, de modo geral, uma coloração rosada, em decorrência da abundante esporulação; a ausência ou escassez de micélio aéreo e as setas curtas resultam em um crescimento rente ao tegumento e aspecto compacto. Comparativamente, nas sementes com $C$. gossypii var. cephalosporioides, as setas são mais longas e menos densas; o micélio aéreo com setas férteis ocorre com mais frequiência, conferindo às sementes tonalidades acinzentadas e aspecto solto. A constatação de setas férteis em lesões foliares de ramulose evidencia que, no campo, essas estruturas podem funcionar como autênticos conidióforos, desempenhando um importante papel epidemiológico, ao possibilitar a disseminação dos esporos pelos ventos, a longas distâncias.
\end{abstract}

Termos de indexação: Colletotrichum, antracnose, ramulose, algodoeiro, sementes.

( ${ }^{1}$ ) Trabalho apresentado no XXI Congresso Brasileiro de Fitopatologia, Salvador (BA), 10 a 17/7/88, e no 5th ISTAPDC Training Course on Detection of Seed-Borne Fungi, Lavras (MG), 11 a 18/9/94. Recebido para publicação em 12 de abril e aceito em 3 de outubro de 1995.

${ }^{2}$ ) Seção de Fitopatologia, Instituto Agronômico (IAC), Caixa Postal 28, 13001-970 Campinas (SP).

(3) Departamento de Fitopatologia, ESALQ/USP, Caixa Postal 9, 13418-260 Piracicaba (SP).

(4) Departamento de Fitossanidade, UfLA, Caixa Postal 37, 37200-000 Lavras (MG).

( ${ }^{5}$ Com bolsa de pesquisa do CNPq. 


\title{
ABSTRACT \\ GROWTH HABIT OF COLLETOTRICHUM GOSSYPII AND C. GOSSYPII VAR. CEPHALOSPORIOIDES ON COTTON SEEDS
}

\begin{abstract}
The growth habit of Colletotrichum gossypii and C. gossypii var. cephalosporioides on artificially inoculated cotton seeds and incubated at $20-22^{\circ} \mathrm{C}$ during 5 to 7 days, showed the following characteristics: (a) on roots: single or coalesced acervuli, conidial mass dirty white, orange or salmon (frequently), dark brown setae, often covered by the gelatinous matrix; conidia also produced from the aerial mycelium or from the apex of the setae, where some of them remain bound to each other, forming small heads; (b) seed surface: the setae arise directly from the seed coat, bearing conidia in the apex. These conidia are seen sticked together, forming clusters resembling chains, bright under stereomicroscope light. The fertile setae are also produced from the aerial mycelium that cover the seeds, generally 5 days after incubation. The acervuli with conidial matrix are rarely visible, except for the embrionary tissues, under the damaged seed coat or for dead seeds. The seeds with $C$. gossypii show generally a light pink shade due to the abundant sporulation that cover the setae. The mycelium over the seeds is scanty or absent and the short setae appear flat on the seeds, resulting in a compact growth. In contrast, on seeds with $C$. gossypii var. cephalosporioides, the setae are taller and less dense. The aerial mycelium with fertile setae is frequent, giving to the seed a grayish and loose, fluffy appearance. The presence of fertile setae also could be seen on foliar lesions of ramulosis. This fact suggest that under field conditions these structures have a function of authentic conidiophores, which play an important epidemiological role on long distance spore dissemination by the wind.
\end{abstract}

Index terms: Colletotrichum, anthracnose, ramulosis, cotton seeds.

\section{INTRODUÇÃO}

Colletotrichum gossypii South. e C. gossypii South. var. cephalosporioides Costa, patógenos causadores da antracnose e da ramulose do algodoeiro (Gossypium hirsutum L.), podem ser transportados tanto interna como externamente pelas sementes, que se constituem num dos principais veículos de sua disseminação (Follin \& Mangano, 1983; Lima et al., 1985; Pizzinatto, 1987).

Tanto a antracnose como a ramulose são consideradas importantes doenças do algodoeiro, podendo causar tombamento de pré- e pós-emergência e redução do estande. Em plantas adultas, a antracnose provoca, principalmente, podridão de maçãs, diminuindo a resistência das fibras e, conseqüentemente, seu valor comercial. A ramulose, no entanto, em virtude dos sintomas que provoca em plantas jovens e adultas, é considerada de importância mais relevante (Carvalho et al., 1984; Lima et al., 1984, 1985). Seus prejuízos podem chegar a $85 \%$ (Cia, 1977; Kimati, 1980;
Carvalho et al., 1984), ou a perdas totais (Tóffano \& Silveira, 1964). O patógeno causa a morte da gema apical, estimulando as gemas axilares a desenvolver número excessivo de ramos, originando sintomas de superbrotamento. Em conseqüência, ocorre um esgotamento das reservas, em detrimento da carga de capulhos, que pode ser nula. As plantas infectadas apresentam-se ramalhudas, com porte abaixo do normal, nós intumescidos, internódios curtos, contorcidos, galhos com manchas alongadas e bronzeadas, folhas com lesões necróticas de formato variável, arredondadas, angulares ou ao longo das nervuras (Kimati, 1980; Watkins, 1981).

No contexto da patologia de sementes, embora se considerem os dois patógenos entre os fungos mais prejudiciais quando associados às sementes de algodoeiro (Pizzinatto, 1987; Tanaka, 1990; Pizzinatto et al., 1994), C. gossypii var. cephalosporioides reveste-se de importância maior, em virtude das perdas que ocasiona à produção. No entanto, em análises de sanidade de sementes, pelos métodos 
rotineiros, a grande semelhança das estruturas de ambos não tem permitido detectar a presença de C. gossypii var. cephalosporioides (Tanaka \& Menten, 1988; Tanaka, 1991).

Observações em sementes de algodoeiro portadoras de C. gossypii e C. gossypii var. cephalosporioides (Tanaka \& Menten, 1988; Tanaka, 1991) evidenciaram características, no hábito de crescimento dos dois patógenos, que necessitam ser investigadas. Com base nessas evidências, o presente trabalho objetivou examinar detalhes inerentes ao hábito de crescimento desses fungos, cujas possíveis diferenças permitam-lhes a distinção e sirvam, futuramente, para embasar-lhes a detecção em testes de sanidade de sementes.

\section{MATERIAL E MÉTODOS}

O experimento desenvolveu-se em $1987 / 88$, nas dependências do Departamento de Fitopatologia da ESALQ-USP, em Piracicaba (SP). Foram utilizadas sementes do cultivar CNPA-2H, deslintadas em ácido sulfúrico e submetidas à assepsia superficial com hipoclorito de sódio a $1 \%$ por três minutos.

Após secagem ao ar e à sombra, em papel absorvente, durante 24 horas, amostras de 200 sementes foram inoculadas com seis isolados de C. gossypii e seis de C. gossypii var. cephalosporioides, para garantir sua precisa identidade e eliminar possível variação entre isolados.

Como inóculo, foram utilizadas culturas puras desenvolvidas em placas de Petri de $9 \mathrm{~cm}$ de diâmetro, com BDA, durante 8 a 10 dias, em condição ambiente de laboratório, com temperatura variando entre 25 e $28^{\circ} \mathrm{C}$. Em cada placa, colocaram-se 50 sementes em contacto com a superfície das colônias, num procedimento semelhante ao descrito por Tanaka et al. (1989). As placas foram agitadas levemente para que toda a superfície das sementes entrasse em contacto com as colônias, permitindo maior adesão do inóculo. A incubação foi realizada nas mesmas condições de laboratório, durante 24 horas.

Após a inoculação, as sementes foram submetidas ao teste de sanidade pelo método do papel de filtro, que consistiu na incubação em placas de Petri de plástico de $9 \mathrm{~cm}$ de diâmetro, forradas com três folhas de papel de filtro umedecidas com água destilada. As placas, contendo cada uma dez sementes eqüidistantes entre si, foram colocadas durante 5 a 7 dias a $20-22^{\circ} \mathrm{C}$, fotoperíodo de 12 horas de escuro e 12 de luz, fornecida por duas lâmpadas fluorescentes brancas (tubos de $120 \mathrm{~cm}$ ) de $40 \mathrm{~W}$, distantes $25 \mathrm{~cm}$ uma da outra e $40 \mathrm{~cm}$ acima das placas.

Após a incubação, as sementes e plântulas foram examinadas, atentando-se para os detalhes das estruturas dos fungos, com o auxílio de estereomicroscópio e microscópio composto.

Em casa de vegetação, plantas do cultivar CNPA $2 \mathrm{H}$, com 30 dias de idade, foram inoculadas com os isolados de cada patógeno, para comprovação de sua patogenicidade e tipo de sintomas provocados. O inóculo de cada isolado, na concentração de $10^{5}$ esporos $/ \mathrm{ml}$, foi pulverizado em quatro plantas, mantidas em câmara úmida durante 48 horas, em casa de vegetação. Vinte dias depois da inoculação, as plantas foram avaliadas quanto aos sintomas apresentados.

\section{RESULTADOS E DISCUSSÃO}

Nas observações realizadas nas raízes das plântulas e na superfície das sementes, não houve variação no hábito de crescimento em relação ao isolado de cada patógeno utilizado.

\section{Em raízes}

Em estereomicroscópio, verificou-se que o hábito de crescimento de ambos os patógenos foi bastante semelhante, com formação de acérvulos isolados ou em grupos, coalescentes nas raízes muito infectadas ou nas lesões mais velhas (Figura 1). Os conídios podem ser produzidos nos conidióforos curtos dos acérvulos, formando a massa conidial gelatinosa característica do gênero Colletotrichum, como também nos ápices de algumas setas, onde podem ficar aglomerados e se apresentam brilhantes sob a luz (Figuras 2, 19 e 20). 
A massa conidial do acérvulo apresenta-se de cor branco-suja, alaranjada ou salmão (mais freqüente). Sob condições de alta umidade, os conídios podem ser produzidos também em conidióforos formados a partir do micélio que se desenvolve sobre as raízes.

Em lâminas preparadas com acérvulos de raízes, pode-se observar que, neles, as setas emergem quase sempre individualmente e eretas, a maioria é fértil (Figura 21a), sendo algumas estéreis (Figura 21b). É frequiente ocorrerem ramificações nos ápices das setas (Figura 21c), onde alguns conídios ficam aderidos, bem como nas suas laterais.

\section{Na superfície das sementes}

As setas podem ser observadas, em estereomicroscópio, isoladas ou em tufos, sobre o tegumento das sementes. São em geral flexuosas, mais longas do que aquelas observadas nas raízes e frequientemente ramificadas (Figura 22). Podem ser formadas também no micélio que recobre as sementes, geralmente após 5 dias de incubação (Figura 3).

Os conídios podem ser vistos brilhantes sob a luz, nos ápices das setas, aderidos uns aos outros, lembrando, à primeira vista, cadeias de extensões variáveis (Figuras 4, 5 e 6).

Os acérvulos com a massa conidial gelatinosa raramente são visíveis, a não ser em sementes mortas (Figura 7). Em locais danificados do tegumento, no entanto, é comum serem vistos sobre os tecidos embrionários expostos (Figura 8).
Em lâminas montadas com fita adesiva transparente, ou em exames diretamente da superfície das sementes, ao microscópio composto, pode-se ver, com maior detalhe, que os conídios formam arranjos que mais se assemelham a cachos (Figuras 9,10 e 23a). Esses cachos se desfazem com facilidade ao se colocar água ou azul de Amann (Figura 23b), permanecendo os conídios jovens e de menor tamanho ligados aos ápices das setas (Figuras $11,12,14,24$ e 25). Antes de serem liberados, alguns conídios podem ser observados no interior dos ápices das setas (Figuras 11, 12 e 23c).

As setas emergem do tegumento apoiadas em uma estrutura estromática, são marrom-escuras, geralmente flexuosas, septadas, podendo ser ramificadas em qualquer ponto de sua extensāo (Figuras 24 e 25). Frequientemente, ocorrem flexőes em forma de cotovelo ao longo de sua extensão (Figuras 13 e 24). A tonalidade das setas vai-se tornando mais clara à medida que se aproxima do ápice, que é hialino e se cora de azul de Amann, como os conídios (Figuras 11, 12 e 14).

As setas férteis, presentes no micélio, dele se originam diretamente, funcionando como conidióforos (Figura 26). São de tamanho variável, septadas, podendo ou não se ramificar, à semelhança do que foi observado para as setas do tegumento. Os conídios formados e aderidos nos seus ápices, no entanto, estão dispostos em pequenos cachos ou em aglomerados formando "cabeças" (Figura 3).

Com a finalidade de caracterizar o hábito de crescimento dos dois patógenos e detectar as diferenças entre eles, observou-se, em estereomicroscópio, que as sementes com C. gossypii exibem

Figuras 1 a 8. Estruturas de Colletotrichum gossypii e C. gossypii var. cephalosporioides observadas em estereomicroscópio. 1. Raiz com acérvulos coalescentes de C. gossypii var. cephalosporioides, com abundante formação de matriz gelatinosa $(25 \mathrm{X})$. 2. Conídios em ápices de setas, em acérvulos de C. gossypii var. cephalosporioides, em raiz $(60 \mathrm{X})$. 3. Setas férteis de $C$. gossypii var. cephalosporioides originadas no micélio aéreo que recobre as sementes $(50 \mathrm{X})$. 4. Conídios nos ápices das setas, aderidos uns aos outros, em configurações que se assemelham a cadeias $(25 \mathrm{X})$. 5. Setas de C. gossypii var. cephalosporioides na superfície de sementes, com cachos de conídios aderidos nos seus ápices (64 X). 6 . Conídios de C. gossypii nos ápices das setas, formando cachos mais longos do que os de C. gossypii var. cephalosporioides $(50 \mathrm{X})$. 7. Formação de acérvulos no tegumento de sementes mortas, cobertos pela matriz gelatinosa e abundante esporulação pelas setas $(30 \mathrm{X})$. 8. Acérvulos de C. gossypii var. cephalosporioides, com massa conidial gelatinosa de cor salmão, em local danificado do tegumento $(9 \mathrm{X})$. 

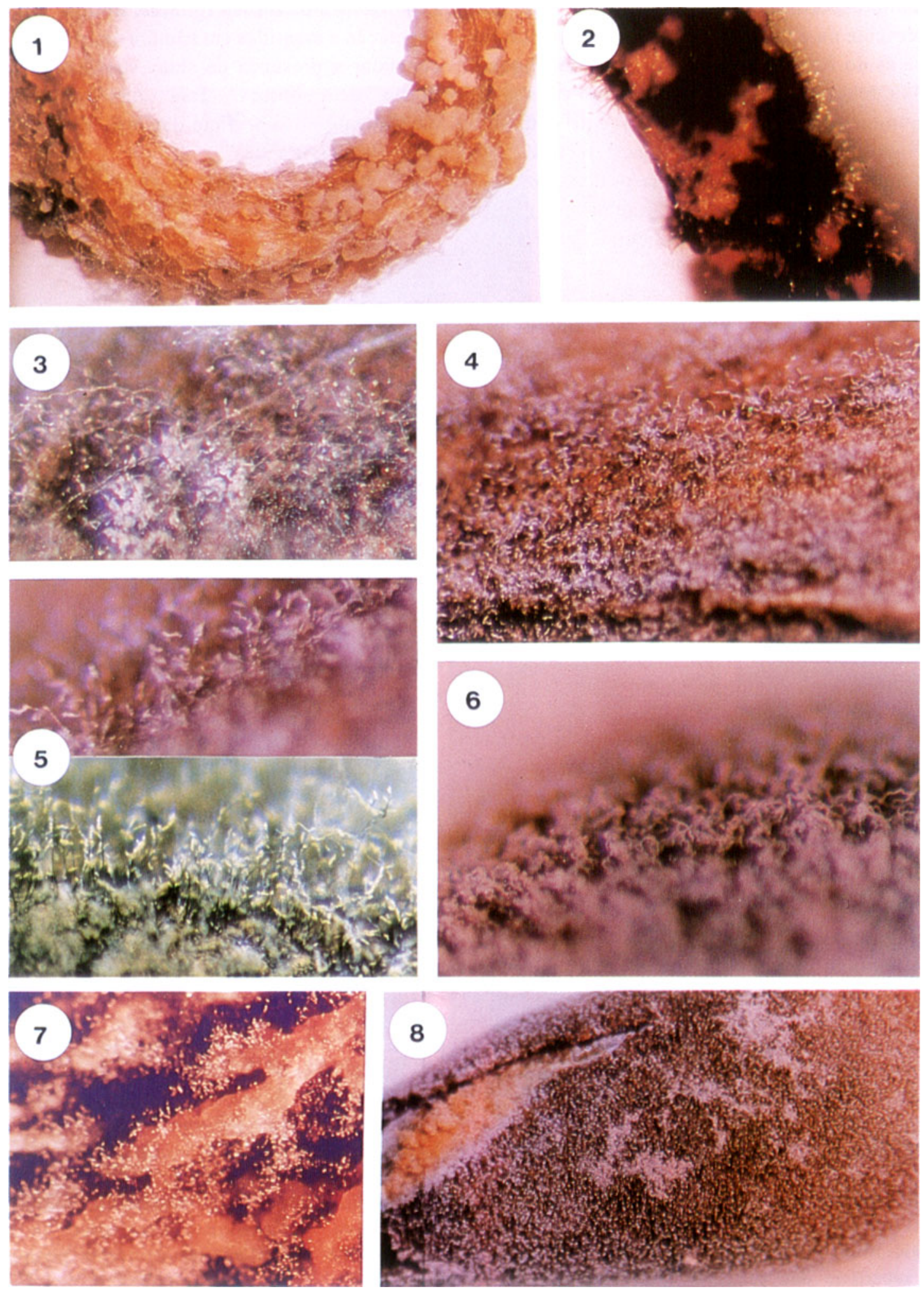
uma coloração mais rosada, em decorrência da abundante esporulação. O micélio geralmente não está presente ou é escasso e as setas são mais curtas do que as do fungo causador da ramulose (Figuras 14 e 17), resultando em um crescimento mais rente ao tegumento (Figura 16). Os cachos de conídios, observados nos ápices das setas formadas no tegumento, são mais longos do que os de C. gossypii var. cephalosporioides, dificultando, em alguns casos, a visualização das setas, que ficam encobertas pela massa conidial (Figura 6).

Em sementes com $C$. gossypii, observou-se, ain$\mathrm{da}$, que os conídios podem ser formados, predominantemente, de conidióforos curtos e hialinos, freqüentemente ramificados, no topo dos quais ficam aderidos, formando "cabeças" (Figuras 14 e 27).

Comparativamente, nas sementes com C. gossypii var. cephalosporioides, as setas que emergem do tegumento são mais longas e menos densas (Figuras 5 e 15). O micélio com setas férteis é freqüente, o que confere às sementes tonalidades acinzentadas e aspecto menos compacto (Figura 16).

Nas inoculações realizadas em casa de vegetação, apenas os isolados de C. gossypii var. cephalosporioides causaram lesões nas folhas e nos pecíolos e provocaram superbrotamento (Figura 18).
Em lâminas preparadas com C. gossypii var. cephalosporioides de lesões foliares, obtidas em casa de vegetação e mantidas em câmara úmida, foi possível constatar a presença de setas com abundante produção de esporos. Tais setas foram formadas diretamente na superfície das lesões ou no micélio presente (Figura 28).

É possível inferir, portanto, que, nas lesões de ramulose, as setas também devem estar funcionando como conidióforos, o que permite algumas consideraçōes do ponto de vista epidemiológico. Corroborando com Lenné et al. (1984), admite-se que os conídios produzidos na matriz gelatinosa dos acérvulos e aqueles produzidos pelas setas devem possuir, na natureza, diferentes mecanismos de disseminação. Os primeiros são disseminados principalmente por respingos de chuva, água de irrigação e, possivelmente, insetos, ficando o seu raio de alcance restrito a distâncias relativamente curtas. Por outro lado, os conídios produzidos pelas setas são disseminados principalmente pelos ventos, alcançando, portanto, longas distâncias e adquirindo uma importância epidemiológica maior. Isso explica a disseminação rápida do patógeno, atingindo grandes áreas de cultivo.

A produção de conídios nas extremidades das setas, fato já relatado para C. gossypii (Atkinson, 1891; Southworth, 1891), C. gossypii var. cephalosporioides (Malagutti, 1955) e outras espécies de Colletotrichum (Sonoda et al., 1974; Lenné et al.,

Figuras 9 a 17. Estruturas de C. gossypii e C. gossypii var. cephalosporioides observadas em microscópio composto. 9 e 10. Arranjos dos conídios formando cachos nos ápices das setas de C. gossypii (9) e C. gossypii var. cephalosporioides (10), na superfície de sementes $(160 \mathrm{X})$. 11. Conídios de C. gossypii, após serem deslocados dos arranjos em forma de cachos. Conídio jovem e de menor tamanho aderido aos ápices das setas $(400 \mathrm{X})$. 12. Setas de $C$. gossypii, ramificadas e mais escuras na base: ápice hialino, contendo no interior um conídio em formação $(400 \mathrm{X})$. 13. Setas de C. gossypii var. cephalosporioides, ramificadas na base, e com flexão em forma de cotovelo $(400 \mathrm{X})$. 14. Setas de C. gossypii, eretas ou ramificadas, mais curtas do que em C. gossypii var. cephalosporioides, facilmente encobertas pela abundante esporulação $(400 \mathrm{X})$. 15. Detalhe de uma seta de $C$. gossypii var. cephalosporioides, mais longa do que as setas de $C$. gossypii $(400 \mathrm{X})$. 16. Hábito de crescimento típico de $C$. gossypii (direita), com estruturas desenvolvidas rente ao tegumento e ausência de micélio aéreo. Semente com C. gossypii var. cephalosporioides (esquerda), com abundante micélio aéreo e aspecto menos compacto (8 X). 17. Conidióforos de C. gossypii, hialinos, curtos e ramificados, que podem ocorrer de forma predominante na superfície das sementes $(400 \mathrm{X})$.

Figura 18. Lesões foliares de ramulose (C. gossypii var. cephalosporioides), dez dias após a inoculação em casa de vegetação. 

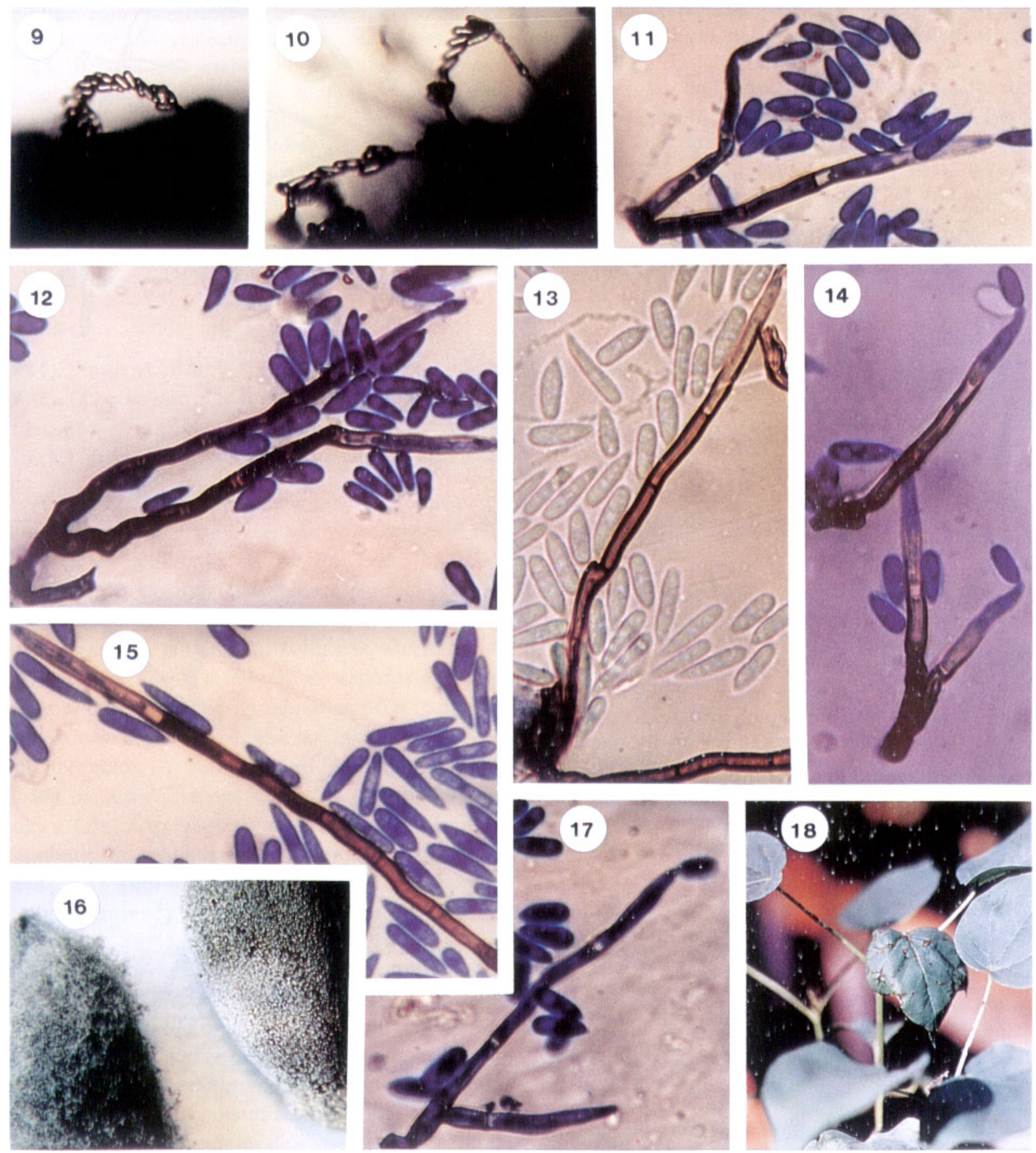

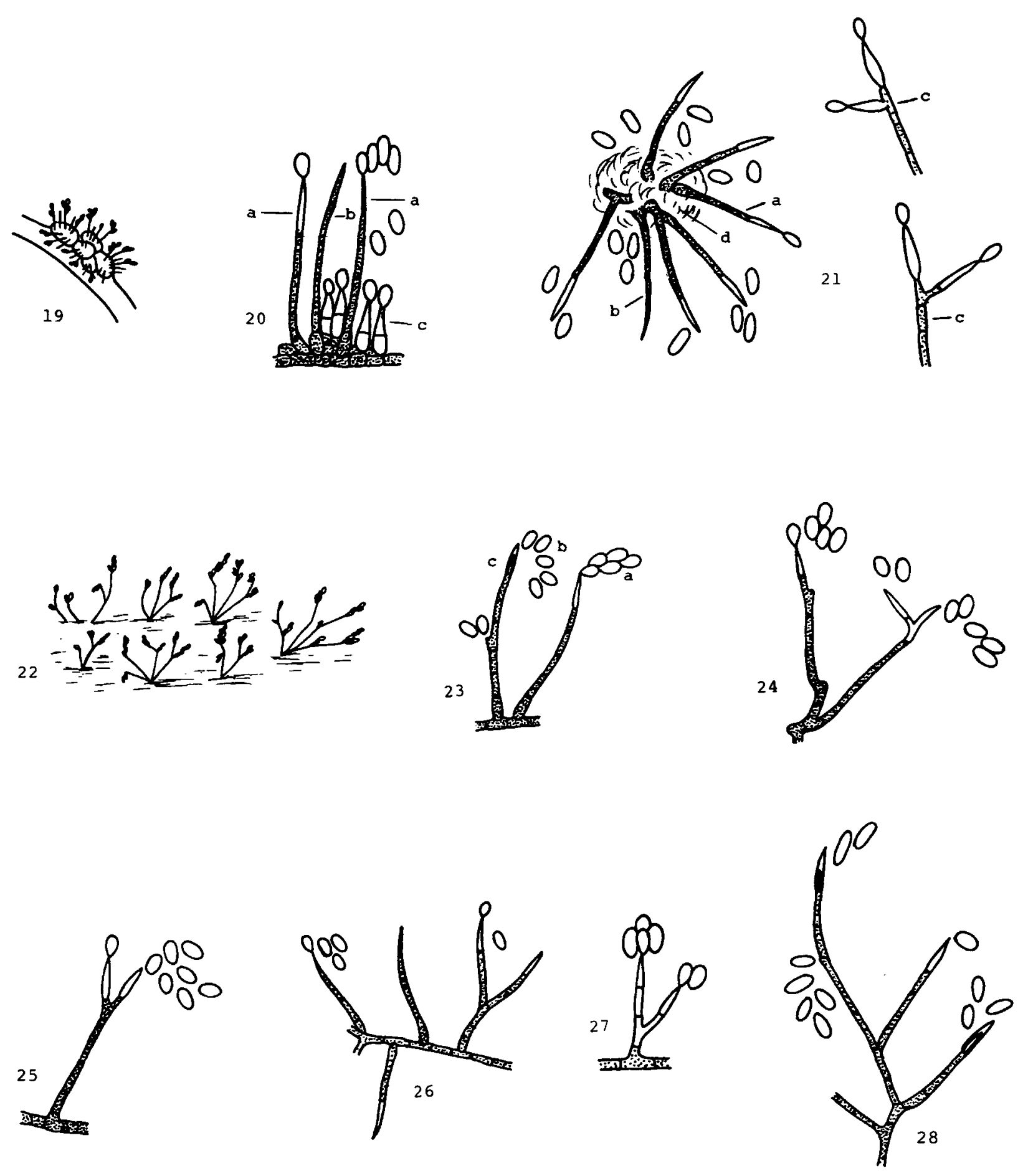
Figuras 19 a 28. Representações esquemáticas do hábito de crescimento de C. gossypii e C. gossypii var. cephalosporioides. 19. Aspecto geral, esquemático, de raízes, com massa conidial gelatinosa e formaçāo de conídios nos ápices de algumas setas. 20. Setas férteis (a), estéreis (b) e conidióforos curtos (c) em acérvulos de raízes. 21. Setas férteis (a) e estéreis (b) de acérvulos de raízes; detalhes de ápices de setas com ramificações (c); massa conidial da matriz gelatinosa(d). 22. Aspecto geral das setas na superfície das sementes: detalhes da disposição dos conídios nos ápices das setas, em estereomicroscópio. 23. Detalhe dos cachos de conídios nos ápices das setas (a); conídios deslocados pela água ou azul de Amann (b); conídio no interior do ápice, antes da liberação (c). 24. Setas flexuosas, com ramificações na base e no ápice, observadas com freqüencia sobre o tegumento das sementes: detalhe de flexões em forma de cotovelo; conídio jovem aderido ao ápice de uma seta. 25. Seta ereta, com ramificação apenas no ápice: detalhe do conídio jovem aderido ao ápice e demais conídios deslocados de cacho desfeito. 26. Setas férteis formadas no micélio aéreo, sobre o tegumento das sementes. 27. Conidióforos hialinos e curtos, com poucos conídios aderidos aos ápices, formando "cabeças": estruturas freqüentemente observadas em C. gossypii. 28. Setas férteis funcionando como conidióforos, em lesões foliares de ramulose.

1984; Smith \& Black, 1990; Gunnell \& Gubler, 1992), faz com que elas funcionem como autênticos conidióforos, e não sejam simplesmente estruturas estéreis dos acérvulos, sem uma função definida.

Atkinson (1891) verificou que a produção de setas férteis por $C$. gossypii ocorre com menor freqüência em substratos tenros. Por outro lado, em substratos de consistência mais rígida, as setas emergem em grande quantidade. O autor observou que, quando os tecidos das folhas se vão tornando mais secos e duros, o número de esporos do fungo tende a diminuir, sendo produzidos principalmente nos ápices das setas e não na matriz gelatinosa dos acérvulos. A maior quantidade de setas verificada na superfície das sementes, em comparação com a raiz, no presente trabalho, resultou, provavelmente, da maior rigidez do tegumento, em relação aos tecidos tenros da raiz da plântula recém-germinada.

\section{CONCLUSÕES}

1. Colletotrichum gossypii e C. gossypii var. cephalosporioides apresentam características no hábito de crescimento que podem ser utilizadas para a sua identificação nas sementes de algodoeiro incubadas.

2. A presença de setas férteis do patógeno em lesões foliares de ramulose evidencia a possibilidade de disseminação dos esporos pelos ventos, a longas distâncias, e adquire um significado epide- miológico muito importante, que deve ser considerado ao estabelecer padrões de tolerância para a presença do patógeno na semente.

\section{REFERÊNCIAS BIBLIOGRÁFICAS}

ATKINSON, G.F. Anthracnose of cotton. Journal of Mycology, Washington, 6(1):173-178, 1891.

CARVALHO, L.P.; CAVALCANTI, F.B.; LIMA, E.P. \& SANTOS, E.O. Influência da ramulose nas características de fibra e produção do algodoeiro. Fitopatologia Brasileira, Brasília, 9(3):593-598, 1984.

CIA, E. Ocorrência e conhecimento das doenças do algodoeiro anual Gossypium hirsutum L. no Brasil. Summa Phytopathologica, Piracicaba, 3(3):167-193, 1977.

FOLLIN, J.C. \& MANGANO, V. Étude sur la ramulose du cotonier. Cotton et Fibres Tropicales, Paris, 38(2):209-215, 1983.

GUNNELL, P.S. \& GUBLER, W.D. Taxonomy and morphology of Colletotrichum species pathogenic to strawberry. Mycologia, New York, 84(2):157-165, 1992.

KIMATI, H. Doenças do algodoeiro - Gossypium spp. In: GALLI, F., ed. Manual de Fitopatologia. São Paulo, Ceres, 1980. v.2, p.29-48.

LENNÉ, J.M.; SONODA, R.M. \& PARBERY, D.G. Production of conidia by setae of Colletotrichum species. Mycologia, New York, 76(2):359-362, 1984. 
LIMA, E.F.; CARVALHO, L.P.; SANTOS, E.O. \& CARVALHO, J.M.F.C. Avaliação de germoplasma de algodoeiro para resistência à ramulose causada por Colletotrichum gossypii. Fitopatologia Brasileira, Brasília, 9(3):561-565, 1984.

LIMA, E.F.; CARVALHO, J.M.F.C.; CARVALHO, L.P. \& COSTA, J.N. Transporte e transmissibilidade de Colletotrichum gossypii var. cephalosporioides através da semente do algodoeiro. Fitopatologia Brasileira, Brasília, 10(1):99-109, 1985.

MALAGUTTI, G. La escobilla del algodón en Venezuela. Agronomia Tropical, Maracay, 5(1):73-83, 1955.

PIZZINATTO, M.A. Testes de sanidade de sementes de algodão. In: SOAVE, J. \& WETZEL, M.M.V.S., eds. Patologia de sementes. Campinas, Fundação Cargill, 1987. p.331-346.

PIZZINATTO, M.A.; CIA, E. \& FUZATTO, M.G. Relação entre a severidade de ramulose do algodoeiro em condições de campo e a presença de Colletotrichum gossypii var. cephalosporioides nas sementes produzidas. Fitopatologia Brasileira, Brasília, 19(1):50-54, 1994.

SMITH, B. \& BLACK, L.L. Morphological, cultural and pathogenic variation among Colletotrichum species isolated from strawberry. Plant Disease, St. Paul, 74(1):69-76, 1990.

SONODA, R.M.; KRETSCHMER JR., A.E. \& BROLMANN, J.B. Colletotrichum leaf spot and stem canker of Stylosanthes spp. in Florida. Tropical Agriculture, Trinidad, 51(1):75-79, 1974.
SOUTHWORTH, E.A. Anthracnose of cotton. Journal of Mycology, Washington, 6(1):100-105, 1891.

TANAKA, M.A.S. Patogenicidade e transmissão por sementes do agente causal da ramulose do algodoeiro. Piracicaba, 1990. $111 \mathrm{p}$. Tese (Doutoramento) ESALQ/USP, 1990.

TANAKA, M.A.S. Problemas da detecção do agente causal da ramulose em sementes de algodão. In: MENTEN, J.O.M. Patógenos em sementes: detecção, danos e controle químico. Piracicaba, ESALQ/FEALQ, 1991. p.93-108.

TANAKA, M.A.S. \& MENTEN, J.O.M. Colletotrichum gossypii e Colletotrichum gossypii var. cephalosporioides em sementes de algodão. Fitopatologia Brasileira, Brasília, 3(2):125, 1988.

TANAKA, M.A.S.; MENTEN, J.O.M. \& MARIANNO, M.I.A. Inoculação artificial de sementes de algodão com Colletotrichum gossypii var. cephalosporioides e infecção das sementes em função do tempo de exposição ao patógeno. Summa Phytopathologica, Jaguariúna, 15(3/4):232-237, 1989.

TÓFFANO, W.B. \& SILVEIRA, A.P. Fusariose e ramulose do algodoeiro. Campinas, Secretaria da Agricultura do Estado de São Paulo, DATE/SIR, 1964. 16p. (Série D/n. ${ }^{\circ} 8$ )

WATKINS, G.M. Compendium of cotton diseases. St. Paul, American Phytopathological Society, 1981. $87 \mathrm{p}$. 